\title{
Karakteristik, Klasifikasi, dan Pengelolaan Tanah yang Terbentuk di Daerah Gunung Api Jaboi Kota Sabang
}

(Characteristics, Classification, and Management of Soil Formed in Jaboi Volcano Sabang City)

\author{
Jhoni Setiawan ${ }^{1}$, Abubakar Karim ${ }^{1}$, Teti Arabia ${ }^{1 *}$ \\ ${ }^{1}$ Program Studi Ilmu Tanah, Fakultas Pertanian, Universitas Syiah Kuala \\ *Corresponding author: tetiarabia@ unsyiah.ac.id
}

\begin{abstract}
Abstrak. Kota Sabang memiliki luas 12.061,08 ha, yang terdiri dari pulau-pulau kecil, yaitu: Pulau Weh, Pulau Klah, Pulau Rubiah, Pulau Seulako, dan lain-lain. Pulau kecil ini terbentuk karena adanya gerakan vulkanik berupa letusan gunung Seulawah yang mengakibatkan pulau ini terpisah dari daratan Aceh Besar. Penelitian ini bertujuan untuk mengetahui karakteristik, klasifikasi, serta pengelolaan tanah-tanah yang terbentuk di daerah gunung api Jaboi Kota Sabang. Metode yang digunakan yaitu survai deskriptif kuantitatif. Parameter yang diukur di lapangan berupa karakteristik morfologi diantaranya: warna dan kedalaman tanah. Dilaboratorium berupa karakteristik fisika tanah adalah tekstur tanah; karakteristik kimia tanah yaitu C-organik dan kejenuhan basa serta jenis mineral tanah. Hasil penelitian menunjukkan bahwa karakteristik dan klasifikasi tanah Alfisol adalah: (a) epipedon molik karena memiliki solum tanah $\geq 18 \mathrm{~cm}(23 \mathrm{~cm})$, kandungan C-organik $\geq 0,6 \%(1,29 \%)$, kejenuhan basa $\geq 50 \%$ $(55,72 \%)$ dan value serta chroma $\leq 3$ (value 3 dan chroma 3 ); (b) horison penciri bawah yang dijumpai adalah argilik karena mengandung liat $<15 \%$, maka horison argilik $>3 \%$ lebih liat yang terdapat pada horison $\mathrm{Bt}$ dibandingkan horison di atasnya; (c) subordo dikategorikan Udalf, great group Hapludalf, subgroup Typic Hapludalf, famili Typic Hapludalf, berlempung, campuran, isohipertermik. Pengelolaan yang sesuai tanah Alfisol yaitu dengan olah tanah konvensional.
\end{abstract}

Kata kunci : Gunung api Jaboi, karakteristik tanah, klasifikasi tanah, pengelolaan tanah

\begin{abstract}
Sabang City has an area of 12,061.08 ha, which are consists of small islands, namely: Weh Island, Klah Island, Rubiah Island, Seulako Island, and others. This small island was formed due to a volcanic movement in the form of the Seulawah volcano eruption which resulted in the island being separated from the mainland of Aceh Besar. This study aims to determine the characteristics, classification, and management of soils formed in the Jaboi volcano in Sabang City. The method in this research is used a quantitative descriptive survey. The parameters measured in the field in the form of morphological characteristics include: color and depth of the soil. In the laboratory the characteristics of soil physics are soil texture; soil chemical characteristics are C-organic and base saturation and soil mineral types. The results showed that the characteristics and classification of Alfisol soils were: (a) Molic epipedon because it had soil solum $\geq 18 \mathrm{~cm}(23 \mathrm{~cm})$, C-organic content $\geq 0.6 \%$ (1.29\%), base saturation $\geq 50 \%$ ( 55.72\%) and the value and chroma $\leq 3$ (value 3 and chroma 3 ); (b) the lower characteristic horizon found is argillic because it contains clay $<15 \%$, the argillic horizon $>3 \%$ more clay found in the $\mathrm{Bt}$ horizon compared to the above horizon; (c) subordo is categorized as Udalf, Hapludalf great group, Typic Hapludalf subgroup, Typic Hapludalf family, clay, mixed, isohipertermic. Appropriate management of Alfisol land is conventional tillage.
\end{abstract}

Keywords: Jaboi Volcano, soil characteristics, soil classification, soil management

\section{PENDAHULUAN}

Kota Sabang memiliki luas 12.061,08 ha, yang terdiri dari pulau-pulau kecil diantaranya: Pulau Weh, Pulau Klah, Pulau Rubiah, Pulau Seulako, dan lain-lain. Pulau kecil ini terbentuk karena adanya gerakan vulkanik berupa letusan gunung Seulawah yang mengakibatkan pulau ini terpisah dari daratan Aceh Besar. Pulau vulkanik ini mengalami tiga tahap pengangkatan patahan bumi yang mengakibatkan Pulau Weh terbagi atas tiga teras dengan dataran tertinggi terdapat pada bagian Barat pulau (Distamben Aceh, 2006).

Morfologi tanah adalah sifat-sifat tanah yang dapat diamati dan dipelajari di lapang, klasifikasi tanah adalah ilmu yang mempelajari cara-cara membedakan sifat-sifat tanah satu sama lain, dan mengelompokkan tanah ke dalam kelas-kelas tertentu berdasarkan atas 
kesamaan sifat yang dimiliki (Hardjowigeno, 2003). Klasifikasi tanah dalam hubungannya dengan pengelolaan tanah yaitu dengan mengetahui nama suatu jenis tanah tertentu dapat diketahui sifat-sifat tanahnya, sehingga dapat diketahui potensi tanah tersebut. Dengan mengetahui potensi tanahnya dapat dibuat suatu sistem pengelolaan untuk tanah tersebut.

Berdasarkan peta jenis tanah yang penulis dapatkan dari BAPPEDA Provinsi Aceh, dapat diindikasikan bahwa jenis tanah yang terdapat di Kota Sabang adalah Andisol dan Ultisol. Namun, hasil dari peta jenis tanah tersebut tidak disertai oleh data-data pendukung yang merujuk bahwa jenis tanah tersebut adalah Andisol dan Ultisol. Berdasarkan uraian di atas mengenai morfologi, klasifikasi, dan pengelolaan tanah, serta belum terdapatnya penelitian di daerah Gunug Api Jaboi kota Sabang, namun dengan dilaksanakan penelitian ini diharapkan mampu memberikan informasi mengenai morfologi, klasifikasi, dan pengelolaan tanah-tanah yang terbentuk di daerah gunung api Jaboi Kota Sabang.

\section{METODE PENELITIAN}

\section{Tempat dan Waktu Penelitian}

Penelitian ini telah dilaksanakan pada tanggal 1 - 8 April 2019 di daerah gunung berapi Jaboi, Kota Sabang. Dilanjutkan dengan analisis kimia dan fisika tanah di Laboratorium Tanah dan Tanaman serta Fisika Tanah untuk melihat beberapa indikator yang dimulai dari tanggal 9 April - 18 Juni 2019.

\section{Alat dan Bahan Penelitian}

Adapun alat yang digunakan dalam penelitian ini adalah cangkul, sekop, bor tanah, buku munsell, spidol permanen, pisau, meteran, $\mathrm{pH}$ tancap, abney level, plastik $2 \mathrm{~kg}$, karet gelang, perlengkapan alat tulis, kamera atau handphone, GPS (global positioning system), kartu deskripsi, ring sample, kartu deskripsi profil dan alat-alat pendukung lainnya.

Adapun bahan yang digunakan dalam penelitian ini adalah peta administrasi, peta kerja, peta penggunaan lahan, peta jenis tanah, peta geologi Kota Sabang, aquades, larutan $\mathrm{HCl}$ dan larutan $\mathrm{H}_{2} \mathrm{O}_{2}$, untuk menganalisis sifat-sifat tanah di lapangan serta beberapa bahan kimia yang digunakan untuk analisis laboratorium.

\section{Metode Penelitian}

Penelitian ini dilakukan dengan menggunakan metode survai deskriptif-kuantitatif (terukur). Titik pengamatan juga mempertimbangkan peta jenis tanah Kota Sabang. Titik pemboran sesuai dengan topografi (ketinggian dari muka laut) yang terdapat pada Gunung Api Jaboi. Profil akan dibuat pada titik-titik pemboran yang berbeda dan pengamatan sifat-sifat tanah di lapangan dan pengambilan sampel tanah untuk dianalisis di laboratorium.

Banyak cara dalam menentukan klasifikasi suatu jenis tanah, mula-mula tanah diklasifikasikan terlebih dahulu ke dalam kategori tertinggi dalam klasifikasi tanah yaitu ordo. Ketika ordo suatu jenis tanah sudah diketahui maka selanjutnya diklasifikasikan ke dalam subordo, great group, subgrup, famili hingga ke seri tanah sesuai dengan perbedaan yang dimiliki oleh setiap jenis tanah.

Menentukan klasifikasi tanah ke dalam masing-masing kategori dapat dilakukan dengan membandingkan sifat-sifat yang dimiliki oleh suatu jenis tanah dengan kriteria-kriteria untuk berbagai taksa yang terdapat di dalam Kunci Taksonomi Tanah (Soil Survey Staff, 2014). 


\section{Pembuatan dan Pengamatan Profil Tanah di Lapangan}

Sifat-sifat tanah dapat dilihat dan diketahui dengan jelas melalui pembuatan lubang profil. Pembuatan profil tanah dapat dilaksanakan dengan dua cara. Cara pertama dengan pembuatan pedon tanah dengan penggalian profil dengan panjang $\mathrm{x}$ lebar $\mathrm{x}$ dalam $(150 \mathrm{~cm} \mathrm{x}$ $100 \mathrm{~cm} \times 150 \mathrm{~cm}$ ). Cara kedua yaitu dengan mengamati tebing-tebing yang sudah tersingkap dengan cara membersihkan tebing-tebing tersebut untuk dibuat menjadi profil tanah sehingga tampak horisonnya dari lapisan atas hingga sampai terdapat lapisan bahan induk. Penelitian ini dilakukan dengan cara yang penggabungan antara yang pertama dan kedua.

Setelah pembuatan pedon tanah selanjutnya dilaksanakan pengisian data profil tanah yang meliputi pengamatan terhadap keadaan lingkungan lahan seperti cuaca, kelerengan, vegetasi, dan penggunaan lahan berdasarkan visual dan menggunakan Abney level untuk melihat kemiringan lokasi penelitian. Pengamatan morfologi tanah seperti tebal horison, batas horison, batas topografi, struktur tanah, konsistensi, plastisitas, warna matriks dan karatan tanah serta perakaran dapat dilihat pada Tabel 2 dan 3. Warna matriks dan karatan tanah dilihat menggunakan buku Munsell soil colour chart.

\section{Analisis Laboratorium}

Parameter yang dianalisis laboratorium dapat dilihat pada Tabel 1.

Tabel 1. Analisis Fisika, Kimia, dan Mineral Tanah di Laboratorium

\begin{tabular}{|c|c|c|}
\hline No & Karakteristik yang Diamati & Metode/Alat/Rumus \\
\hline 1 & Tekstur tanah tiga fraksi & Pipet (Hukum Stokes) \\
\hline 2 & C-organik tanah & Walkley dan Black \\
\hline 3 & $\mathrm{pH} \mathrm{H}_{2} \mathrm{O}$, dan $\mathrm{pH} \mathrm{KCl}$ & Elektometrik \\
\hline 4 & Basa-basa dd (Ca, Mg, Na dan $\mathrm{K})$ tanah & Ekstrak $1 \mathrm{~N} \mathrm{NH}_{4} \mathrm{OAc} \mathrm{pH} 7$ \\
\hline 5 & Asam-asam dd (Al dan $\mathrm{H})$ & Ekstrak $1 \mathrm{~N} \mathrm{KCl}$ \\
\hline 6 & Kapasitas tukar kation (KTK) & Ekstrak $1 \mathrm{~N} \mathrm{NH}_{4} \mathrm{OAc} \mathrm{pH} 7$ \\
\hline 7 & Kejenuhan basa (KB) & $\frac{\sum \text { Basa }- \text { basa dd }}{\text { KTK }} \times 100 \%$ \\
\hline 8 & Extractable acidity (EA) & $\mathrm{BaCl}_{2}$ TEA pH 8,2 \\
\hline 9 & KTK $\sum$ kation & $\sum$ basa-basa dd + EA \\
\hline 10 & KB $\sum$ kation & $\frac{\sum \text { basa }- \text { basa dd }}{\text { Basa }- \text { basa dd }+ \text { EA }}$ \\
\hline 11 & KTK efektif & $\sum$ basa-basa dd $+\mathrm{Al} d \mathrm{~d}$ \\
\hline 12 & Kandungan mineral fraksi liat & XRD (X-ray diffraction) \\
\hline
\end{tabular}

Sumber : Arabia et al. (2012)

\section{Analisis Data}

Analisis data yang dihasilkan dari pengamatan di lapangan dan laboratorium kemudian ditabulasi, dicatat dan disusun secara sistematis serta dikelompokkan berdasarkan kepentingan analisis. Selanjutnya dibahas berdasarkan kriteria parameter pengamatan. 


\section{HASIL DAN PEMBAHASAN}

\section{A. Karakteristik Morfologi Tanah}

Karakteristik morfologi tanah berupa ketebalan horison, batas horison, batas topografi, struktur tanah, konsistensi, plastisitas, warna matriks dan karatan tanah serta perakaran dapat dilihat pada Tabel 2 dan 3 .

Tabel 2. Ketebalan Horison, Batas Horison, Batas Topografi, Struktur Tanah, Konsistensi, dan Plastisitas

\begin{tabular}{lccccccc}
\hline \multirow{2}{*}{$\begin{array}{c}\text { Horison/ } \\
\text { Kedalaman } \\
\text { Tanah }(\mathrm{cm})\end{array}$} & $\begin{array}{c}\text { Tebal } \\
\text { Horison } \\
(\mathrm{cm})\end{array}$ & $\begin{array}{c}\text { Batas } \\
\text { Horison }\end{array}$ & $\begin{array}{c}\text { Batas } \\
\text { Topografi }\end{array}$ & $\begin{array}{c}\text { Struktur } \\
\text { Tanah }\end{array}$ & \multicolumn{2}{c}{ Konsistensi } & \multirow{2}{*}{ Plastisitas } \\
$\mathrm{A} /(0-23)$ & 23 & $\mathrm{~b}$ & 1 & $\mathrm{sd}, \mathrm{bs}, \mathrm{g}$ & $\mathrm{tg}$ & $\mathrm{alk}$ & $\mathrm{pl}$ \\
$\mathrm{AB} /(23-42)$ & 19 & $\mathrm{~b}$ & $\mathrm{p}$ & $\mathrm{sd}, \mathrm{bs}, \mathrm{g}$ & $\mathrm{tg}$ & $\mathrm{alk}$ & $\mathrm{pl}$ \\
$\mathrm{BA} /(42-54)$ & 12 & $\mathrm{a}$ & 1 & $\mathrm{ku}, \mathrm{bs}, \mathrm{gs}$ & $\mathrm{stg}$ & $\mathrm{lk}$ & $\mathrm{spl}$ \\
$\mathrm{Bt} /(54-83)$ & 29 & $\mathrm{~b}$ & 1 & $\mathrm{ku}, \mathrm{bs}, \mathrm{gs}$ & $\mathrm{stg}$ & $\mathrm{lk}$ & $\mathrm{spl}$ \\
$\mathrm{BC} /(83-123)$ & 39 & $\mathrm{~b}$ & $\mathrm{ta}$ & $\mathrm{sd}, \mathrm{sd}, \mathrm{g}$ & $\mathrm{tg}$ & $\mathrm{lk}$ & $\mathrm{spl}$ \\
\hline
\end{tabular}

Keterangan: $\mathrm{b}=$ baur, $\mathrm{a}=$ angsur, $\mathrm{l}=$ lurus, $\mathrm{p}=$ putus, ta = tak beraturan, $\mathrm{sd}=$ sedang, $\mathrm{bs}=\mathrm{besar}, \mathrm{g}=\mathrm{gumpal}$, $\mathrm{ku}=$ kuat, $\mathrm{gs}=$ gumpal bersudut, $\mathrm{tg}=$ teguh, $\mathrm{stg}=$ sangat teguh, alk = agak lekat, $\mathrm{lk}=$ lekat, $\mathrm{pl}=$ plastis, $\mathrm{spl}=$ sangat plastis

\section{Susunan dan Batas Horison}

Tabel 2 menunjukkan hasil pengamatan saat di lapangan tepatnya di sekitaran gunung api Jaboi Kota Sabang. Lokasi tempat pembuatan pedon ini berada di Desa Keneukai yang jumpai lima macam horison penyusun tanah dengan ketebalan hingga $123 \mathrm{~cm}$. Pedon ini dijumpai horison penyusun pertama yaitu horison A yang memiliki ketebalan horison tanah $23 \mathrm{~cm}$. Batas horison baur karena tebal peralihan $>12,5 \mathrm{~cm}(23 \mathrm{~cm})$. Batas topografi lurus karena batas horison datar. Horison $\mathrm{AB}$ yang memiliki ketebalan horison tanah berkisar $19 \mathrm{~cm}$. Horison ini diberi simbol $\mathrm{AB}$ karena telah terjadi peralihan antara horison $\mathrm{A}$ menuju horison $\mathrm{B}$, akan tetapi sifat horison A lebih mendominasi dibandingkan sifat horison B. Batas horison baur dan batas topografi putus karena batas horison tidak menyambung. Horison BA yang memiliki ketebalan horison tanah berkisar $12 \mathrm{~cm}$. Simbol BA diberikan karena horison ini merupakan horison peralihan dari A ke B tetapi lebih mirip sifat ke horison B. Batas horison angsur karena tebal peralihan $6,5-12,5 \mathrm{~cm}(12 \mathrm{~cm})$, batas topografi lurus. Horison ini diberikan simbol $\mathrm{Bt}$ mempunyai sifat penimbunan (iluviasi) liat. Simbol tambahan (t) kecil pada horison ini diberikan karena horison ini memiliki kandungan liat yang tinggi hal ini dapat dibuktikan dengan hasil analisis laboratorium yang menunjukkan terjadinya kenaikan persentase fraksi liat yang pada horison sebelumnya berkisaran $5 \%$ dan naik menjadi $16 \%$. Batas horison baur dan batas topografi lurus. Horison terakhir pada pedon ini adalah horison BC yang memiliki ketebalan horison $39 \mathrm{~cm}$. Horison $\mathrm{BC}$ adalah horison peralihan yang terdiri dari horison $\mathrm{B}$ dan horison C. Namun, sifat yang terdapat pada horison ini cenderung lebih banyak ke horison B dibandingkan dengan horison $\mathrm{C}$. Batas horison baur dan batas topografi tidak beraturan karena batas peralihan tidak beraturan, naik turun.

\section{Struktur, Konsistensi dan Plastisitas}

Struktur tanah pada horison A ini adalah gumpal. Tingkat perkembangan atau kemantapan tanah sedang (medium). Sedangkan untuk ukuran atau kelas struktur yang 
dijumpai adalah besar, dengan ukuran atau kelas struktur berkisar 20 - $50 \mathrm{~mm}$. Konsistensi lembab pada horison ini adalah teguh. Konsistensi basah pada horison ini adalah agak lekat. Kelas plastisitas pada horison A memiliki kelas plastis. Struktur tanah pada horison AB adalah gumpal. Sedangkan tingkat perkembangan atau kemantapan tanah sedang (medium). Tingkat perkembangan atau kemantapan tanah sedang (medium). Sedangkan untuk ukuran atau kelas struktur yang dijumpai adalah besar, dengan ukuran atau kelas struktur berkisar $20-50 \mathrm{~mm}$. Konsistensi lembab pada horison ini adalah teguh. Dikatakan konsistensi teguh ialah keadaan tanah yang memerlukan tekanan yang sedang untuk menghancurkan tanah sampai sama sekali tidak dapat dihancurkan Konsistensi basah pada horison ini adalah agak lekat. Plastisitas horison ini adalah plastis.

Struktur tanah pada horison BA adalah gumpal bersudut (angular blocky). Gumpal bersudut memiliki makna yaitu sumbu vertikal sama dengan sumbu horisontal. Sisi-sisi membentuk sudut tajam. Memiliki tingkat perkembangan atau kemantapan struktur yang kuat (strong). Tingkat perkembangan atau kemantapan struktur yang kuat (strong) adalah butir-butir struktur tidak rusak waktu diambil dari profil tanah dan tetap tidak hancur (rusak) walaupun digerak-gerakan. Ukuran atau kelas struktur yang dijumpai adalah besar, dengan ukuran atau kelas struktur berkisar $20-50 \mathrm{~mm}$. Konsistensi lembab yang dimiliki oleh horison ini adalah sangat teguh. Konsistensi sangat teguh ialah sebuah keadaan tanah dimana memerlukan tekanan yang kuat untuk menghancurkan massa tanah bila diremas sedangkan konsistensi basah pada horison ini memiliki kelas konsistensi basah lekat karena tanah melekat pada jari tangan atau benda lain sedangkan untuk kelas plastisitas pada horison ini memiliki kelas sangat plastis. Sangat platis merupakan kemampuan tanah untuk membentuk gulungan diperlukan tekanan besar untuk merusak gulungan tersebut.

Horison Bt memiliki struktur gumpal bersudut (angular blocky) dan memiliki tingkat perkembangan atau kemantapan struktur yang kuat (strong). Ukuran atau kelas struktur yang dijumpai adalah besar, dengan ukuran atau kelas struktur berkisar 20 - $50 \mathrm{~mm}$. Konsistensi lembab yang ditemukan pada horison ini ialah sangat teguh. Konsistensi basah pada horison ialah lekat karena tanah melekat pada jari tangan atau benda lain, kelas plastisitas pada horison ini memiliki kelas sangat plastis. Horison BC memiliki struktur tanah adalah gumpal. Sedangkan tingkat perkembangan atau kemantapan tanah sedang (medium). Tingkat perkembangan atau kemantapan tanah sedang (medium) adalah butir-butir struktur agak kuat dan tidak hancur (rusak) waktu diambil dari profil untuk diperiksa. Ukuran atau kelas struktur yang dijumpai adalah sedang, dengan ukuran atau kelas struktur berkisar $10-20 \mathrm{~mm}$. Konsistensi lembab adalah teguh, memiliki kelas konsistensi basah lekat karena tanah melekat pada jari tangan atau benda lain sedangkan untuk kelas plastisitas pada horison ini memiliki kelas sangat plastis.

Tabel 3. Warna Matriks dan Karatan Tanah serta Perakaran

\begin{tabular}{|c|c|c|c|c|c|c|c|}
\hline \multirow{2}{*}{$\begin{array}{l}\text { Horison/ } \\
\text { Kedalaman } \\
\text { Tanah }(\mathrm{cm})\end{array}$} & \multirow{2}{*}{$\begin{array}{c}\text { Warna } \\
\text { Matriks } \\
\text { Tanah }\end{array}$} & \multicolumn{5}{|c|}{ Karatan Tanah } & \multirow[b]{2}{*}{ Akar } \\
\hline & & Warna Fe & Jumlah & Ukuran & Bandingan & Bentuk & \\
\hline $\mathrm{A} /(0-23)$ & $7,5 \mathrm{YR}^{3} / 3$ & - & - & - & - & - & $\mathrm{h}$ \\
\hline $\mathrm{AB} /(23-42)$ & $7,5 \mathrm{YR}^{4} / 3$ & $7,5 \mathrm{YR}^{5 / 8}$ & ba & $\mathrm{sd}$ & $\mathrm{p}$ & bi & $\mathrm{h}$ \\
\hline $\mathrm{BA} /(42-54)$ & $7,5 \mathrm{YR}^{3} / 2$ & $2,5 \mathrm{YR}^{4} / 6$ & sd & $\mathrm{h}$ & $\mathrm{b}$ & bi & $\mathrm{h}$ \\
\hline $\mathrm{Bt} /(54-83)$ & $10 \mathrm{YR}^{3} / 2$ & $7,5 \mathrm{YR}^{5 / 6}$ & ba & $\mathrm{sd}$ & $\mathrm{p}$ & bi & $\mathrm{h}$ \\
\hline $\mathrm{BC} /(83-123)$ & $7,5 \mathrm{YR}^{3} / 1$ & - & - & - & - & - & $\mathrm{k}$ \\
\hline
\end{tabular}

Keterangan: $7,5 \mathrm{YR}^{3} / 2$ dan $7,5 \mathrm{YR}^{3} / 3=$ dark brown (coklat gelap), 7,5 YR $4 / 3=$ brown (coklat), 7,5 YR $5 / 6$ dan $7,5 \mathrm{YR} 5 / 8=$ strong brown (coklat kuat), 2,5 YR $4 / 6=$ red (merah), $10 \mathrm{YR} 3 / 2=$ very dark grayish 
brown (coklat keabu-abuan sangat gelap), 7,5 YR 3/1 = very dark grey (kelabusa sangat gelap), ba = banyak, $\mathrm{sd}=$ sedang, $\mathrm{h}=$ halus, $\mathrm{p}=$ prominan, $\mathrm{b}=$ baur, $\mathrm{bi}=$ bintik, $\mathrm{k}=$ kasar

\section{Warna Tanah}

Horison A ini memperlihatkan warna tanah 7,5 YR $3 / 3$ dark brown (coklat gelap). Horison $\mathrm{AB}$ memiliki warna tanah 7,5 $\mathrm{YR}^{4} / 3$ brown (coklat). Karatan berwarna 7,5 $\mathrm{YR}^{5} / 8$ strong brown (coklat kuat). Jumlah yang terkandung dalam horison ini tergolong banyak karena sudah melebihi 20\% keberadaan karatan pada horison ini dengan ukuran sedang dengan diameter 5 $15 \mathrm{~mm}$. Bandingan karatan terdapat pada horison ini prominan (nyata/tegas) dimana karatan tampak menyolok dalam horison. Sedangkan untuk bentuk karatan yang terdapat pada horison ini bintik (bi/spot) dimana bentuk karatan ini saling membulat dan satu dengan lainnya tidak bersambung. Horison BA memiliki warna tanah yaitu 7,5 YR $3 / 2$ dark brown (coklat gelap). Horison ini memiliki karatan, dengan warna karatan 2,5 YR $4 / 6$ red (merah). Karatan yang terkandung dalam horison ini memiliki jumlah sedikit $(<2 \%)$, ukuran karatan halus berdiameter $(<5 \mathrm{~mm})$. Untuk bandingan karatan terdapat pada horison ini prominan. Bentuk karatan yang terdapat pada horison ini bintik (bi/spot). Horison Bt memiliki warna tanah yaitu $10 \mathrm{YR} 3 / 2$ very dark grayish brown (coklat keabu-abuan sangat gelap) dan memiliki karatan, dengan warna karatan 7,5 YR $5 / 6$ strong brown (kecoklatan). Jumlah karatan yang terkandung dalam horison ini tergolong banyak. Bandingan karatan terdapat pada horison ini prominan (nyata/tegas). Sedangkan untuk bentuk karatan yang terdapat pada horison ini bintik (bi/spot). Horison BC memiliki warna tanah pada pedon ini yaitu 7,5 YR $3 / 1$ very dark grey (kelabu sangat gelap) dan tidak terdapat karatan.

\section{B. Karakteristik Fisika Tanah}

Hasil analisis fisika tanah dapat dilihat pada Tabel 4.

Tabel 4. Data Kelas Tekstur Tanah

\begin{tabular}{|c|c|c|c|c|}
\hline \multirow{2}{*}{$\begin{array}{c}\text { Horison/ } \\
\text { Kedalaman } \\
\text { Tanah }(\mathrm{cm}) \\
\end{array}$} & \multicolumn{3}{|c|}{ Tekstur Tanah } & \multirow{2}{*}{ Kelas Tekstur } \\
\hline & Pasir & Debu & Liat & \\
\hline $\mathrm{A} /(0-23)$ & 25 & 69 & 6 & Lempung Berdebu \\
\hline $\mathrm{AB} /(23-42)$ & 16 & 73 & 11 & Lempung Berdebu \\
\hline $\mathrm{BA} /(42-54)$ & 14 & 81 & 5 & Debu \\
\hline $\mathrm{Bt} /(54-83)$ & 35 & 49 & 16 & Lempung \\
\hline $\mathrm{BC} /(83-123)$ & 20 & 75 & 5 & Lempung Berdebu \\
\hline
\end{tabular}

\section{Tekstur Tanah}

Tekstur tanah adalah perbandingan relatif antara fraksi pasir, debu, dan liat, yaitu partikel yang berdiameter efektifnya $\leq 2 \mathrm{~mm}$. Berdasarkan hasil analisis ditemukan bahwa tekstur tanah tersebut debu, lempung berdebu, hingga lempung. Pada horison Bt terjadi penimbunan liat yang ditandai hasil analisis untuk fraksi liat pada horison Bt lebih tinggi dari pada horison di atasnya sehingga dapat dikatakan horison argilik. Horison argilik adalah horison eluviasi mengandung liat $<15 \%$ maka horison argilik $\geq 3 \%$. Pada horison BA terdapat liat sebesar 5\% sedangkan terjadi kenaikan liat sebesar $\geq 3 \%$ pada horison Bt sebesar $16 \%$. 


\section{Karakteristik Kimia Tanah}

Hasil analisis kimia tanah dapat dilihat pada Tabel 5.

Tabel 5. Data Kimia Tanah

\begin{tabular}{|c|c|c|c|c|c|c|c|c|c|c|c|}
\hline \multirow{3}{*}{$\begin{array}{l}\text { Horison/ } \\
\text { Kedalaman } \\
\text { Tanah }(\mathrm{cm})\end{array}$} & \multirow{2}{*}{\multicolumn{2}{|c|}{$\begin{array}{c}\text { Reaksi Tanah } \\
(\mathrm{pH})\end{array}$}} & \multirow{3}{*}{$\begin{array}{c}\text { C- } \\
\text { Organik } \\
(\%)\end{array}$} & \multicolumn{5}{|c|}{ Basa-basa dan Asam dd } & \multirow{2}{*}{ KTK } & \multirow{2}{*}{$\begin{array}{c}\mathrm{KB} p \mathrm{pH} \\
7 \\
\end{array}$} & \multirow{2}{*}{$\begin{array}{c}\mathrm{KB} \mathrm{pH} \\
8,2\end{array}$} \\
\hline & & & & $\mathrm{Ca}$ & $\mathrm{Mg}$ & $\mathrm{K}$ & $\mathrm{Na}$ & $\mathrm{H}$ & & & \\
\hline & $\mathrm{H}_{2} \mathrm{O}$ & $\mathrm{KCl}$ & & \multicolumn{6}{|c|}{ 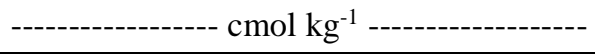 } & \multicolumn{2}{|c|}{------ \% - } \\
\hline $\mathrm{A} /(0-23)$ & 6,1 & 4,7 & 1,3 & 10,6 & 0,4 & 4,2 & 0,2 & 0,3 & 27,6 & 55,7 & - \\
\hline $\mathrm{AB} /(23-42)$ & 6,7 & 4,5 & 0,5 & 11,3 & 0,4 & 0,2 & 0,2 & 0,2 & 25,2 & 47,7 & - \\
\hline $\mathrm{BA} /(42-54)$ & 6,7 & 4,5 & 0,4 & 11,9 & 0,4 & 0,2 & 0,2 & 0,1 & 29,6 & 42,9 & - \\
\hline $\mathrm{Bt} /(54-83)$ & 6,4 & 4,6 & 0,4 & 11,3 & 0,4 & 0,3 & 0,2 & 0,1 & 26,0 & 46,6 & 60 \\
\hline $\mathrm{BC} /(83-123)$ & 6,6 & 4,8 & 0,5 & 12,1 & 0,4 & 0,3 & 0,2 & 0,1 & 29,6 & 43,7 & - \\
\hline
\end{tabular}

\section{Reaksi Tanah (pH)}

Reaksi tanah merupakan salah satu sifat kimia dari tanah yang mencakup berbagai unsurunsur dan senyawa-senyawa kimia yang lengkap. Reaksi tanah menunjukkan tentang keadaan atau status kimia tanah dimana status kimia tanah merupakan suatu faktor yang mempengaruhi proses-proses biologis seperti pada pertumbuhan tanaman. Reaksi atau $\mathrm{pH}$ yang ekstrim berarti menunjukkan keadaan kimia tanah yang dapat disebutkan proses biologis terganggu (Pairunan, 1985). Berdasarkan tabel diatas menunjukkan bahwa $\mathrm{pH}$ tanah $\mathrm{H} 2 \mathrm{O}$ yang terdapat pada lokasi tersebut dikategorikan ke dalam kelas agak masam hingga netral karena memiliki nilai 6,14 hingga 6,68. Sedangkan untuk analisis $\mathrm{pH} \mathrm{KCl}$ tersebut digolongkan kedalam kelas masam karena memiliki nilai 4,46 hingga 4,80.

\section{C-Organik}

Kandungan C-organik tanah memiliki kriteria sangat rendah hingga rendah. Kandungan tersebut berkisar 0,35-1,29\%. Semakin kebawah kandungan C-organik semakin rendah karena sumber bahan organik pada lokasi penelitian berasal dari pengguguran serasah tanaman baik dari ranting, daun, batang hingga akar dari tanaman yang terdapat pada lokasi tersebut. Sehingga nilai yang tertinggi untuk analisis kadungan $\mathrm{C}$-organik tanah terdapat horison permukaan sedangkan horison di bawahnya memiliki nilai kandungan $\mathrm{C}$-organik yang rendah.

\section{Basa-basa Tanah Dapat Dipertukarkan}

Kation basa dapat dipengaruhi oleh curah hujan dan sifat bahan induk. Tingginya curah hujan akan mengaibatkan kandungan basa-basa tanah semakin rendah akibat adanya proses pencucian yang semakin intensif (Arifin, 1994). Nilai basa-basa dapat dipertukarkan pada lokasi penelitian berdasarkan tabel 3 adalah kation Ca-dd tergolong tinggi berkisar 10,60 $12,12 \mathrm{cmol} \mathrm{kg}^{-1}$. Mg-dd tergolong sangat rendah hingga rendah karena memiliki nilai 0,38 $0,40 \mathrm{cmol} \mathrm{kg}^{-1}$. K-dd tergolong rendah hingga sangat tinggi berkisar $0,20-4,23 \mathrm{cmol} \mathrm{kg}^{-1}$. Nadd tergolong rendah karena memiliki nilai berkisar $0,17-0,18 \mathrm{cmol} \mathrm{kg}^{-1}$.

\section{Asam-asam Dapat Dipertukarkan}

Hasil analisis yang telah dilakukan pada profil ini menunjukkan bahwa hanya analisis $\mathrm{H}$ dd saja yang dapat diketahui nilainya sedangkan untuk analisis Al-dd tidak terukur. Hasil analisis H-dd pada lokasi tersebut berkisar $0,12-0,32 \mathrm{cmol} \mathrm{kg}^{-1}$. Kandungan H-dd yang 
terdapat pada tiap-tiap horison ini bervariasi. Semakin kebawah lapisan tanah maka nilai H-dd yang dimiliki semakin kecil.

Hakim et al. (1986), menyatakan dalam keadaan yang sangat masam, Al menjadi sangat larut yang dijumpai dalam bentuk kation $\mathrm{Al}^{3+}$ dan hidroksida $\mathrm{Al}$. Kedua ion $\mathrm{Al}$ itu lebih mudah terjerap pada koloid liat daripada ion $\mathrm{H}$. Oleh karena $\mathrm{Al}$ berada dalam larutan tanah mudah terhidrolisis, maka $\mathrm{Al}$ merupakan penyebab kemasaman atau penyumbang ion $\mathrm{H}$. Ion $\mathrm{H}$ yang dibebaskan secara demikian akan memberikan nilai $\mathrm{pH}$ rendah bagi larutan tanah dan mungkin merupakan sumber utama ion $\mathrm{H}$ dalam sebagian besar tanah masam.

\section{Kapasitas Tukar Kation (KTK)}

Kapasitas tukar kation pada profil ini memiliki nilai berkisar $25,20-29,60 \mathrm{cmol} \mathrm{kg}^{-1}$ dan dikategorikan ke dalam kelas tinggi. Tanah ini mempunyai kejenuhan basa yang tinggi. Kapasitas tukar kation tinggi, dan cadangan unsur hara yang banyak. Bahaya erosi yang perlu diperhatikan pada tanah ini ketika horison argilik muncul di permukaan, tanah menjadi kurang baik (liat terlalu tinggi) (Hardjiwigeno, 2003).

\section{Kejenuhan Basa (KB)}

Hasil analisis yang telah dilaksanakan didapatkan hasil mengenai kejenuhan basa yang bernilai $42,91-55,71 \%$. Berdasarkan hasil tersebut maka dikategorikan ke dalam kelas sangat tinggi. Kejenuhan basa tinggi maka $\mathrm{pH}$ tanah tinggi, karena jika kejenuhan basa rendah berarti banyak terdapat kation-kation masam yang terjerap kuat di koloid tanah (Nyakpa et al., 1988).

\section{Karakteristik Mineralogi}

Hasil analisis mineralogi tanah dapat dilihat pada Tabel 6.

Tabel 6. Karakteristik Mineralogi Tanah

\begin{tabular}{cccc}
\hline Nomor & Angstrom $(\AA)$ & Intensitas & Nama Mineral \\
\hline 1 & 3,29 & 131 & Felspar \\
2 & 3,97 & 77 & Felspar \\
3 & 4,38 & 55 & Kaolinit dan Dikit \\
\hline
\end{tabular}

\section{E. Klasifikasi Tanah}

Sistem klasifikasi tanah yang digunakan dalam penelitian ini adalah berdasarkan Soil Taxonomy (Soil Survey Staff, 2014). Klasifikasi tanah Alfisol dapat dilihat pada Tabel 7.

Tabel 7. Klasifikasi Tanah Alfisol

\begin{tabular}{|c|c|c|c|c|c|c|}
\hline Epipedon & HPB & RK & KBB & $\mathrm{KM}$ & KRS & Nama Tanah \\
\hline Molik & Argilik & Udik & Berlempung & $\begin{array}{l}\text { Campuran } \\
\text { (Felspar, } \\
\text { Kaolinit } \\
\text { dan Dikit) }\end{array}$ & Isohipertermik & $\begin{array}{l}\text { Ordo: Alfisol; } \\
\text { Subordo: Udalf; } \\
\text { Great group: Hapludalf; } \\
\text { Subgrup: Typic Hapludalf; } \\
\text { Famili: Typic Hapludalf, } \\
\text { berlempung, campuran, } \\
\text { isohipertermik. }\end{array}$ \\
\hline
\end{tabular}

Keterangan: HPB (horison penciri bawah); RK (rejim kelembaban); KBB (kelas besar butir); KM (kelas mineralogi); KRS (kelas rejim suhu) 
Alfisol yang terdapat di daerah gunung api Jaboi Kota Sabang dicirikan memiliki horion penciri atas molik, karena memiliki horison permukaan yang tebal $\geq 18 \mathrm{~cm}$ sebesar $23 \mathrm{~cm}$. Horison ini memiliki value lembab $\leq 3$. Untuk kandungan C-organik tanah yang dimiliki pada tanah ini sebesar 1,29\% sesuai dengan kriteria sifat molik yang memiliki kandungan C-organik $\geq 0,6 \%$. Kejenuhan basa yang dimiliki pedon ini bernilai 55,72\%. Horison penciri bawah pada pedon ini adalah argilik, karena salah satu horison memenuhi syarat argilik yaitu bila horison eluviasi mengandung liat $<15 \%$, maka horison argilik $\geq 3 \%$ (absolut) lebih liat. Horison tersebut menunjukkan bukti adanya illuviasi liat. Horison argilik terbentuk di bawah permukaan tanah, tetapi di kemudian hari akibat erosi, horison ini dapat tersingkap di permukaan tanah (Soil Survey Staff, 2014).

Kategori ordo adalah Alfisol karena memiliki Tanah ini memiliki horison argilik pada horison Bt dengan $\mathrm{KB}$ pH 8,2 $\geq 35 \%$ pada kedalaman 1,8 $\mathrm{m}$. Hasil kejenuhan basa dengan $\mathrm{pH}$ 8,2 dapat dilihat pada Tabel 3. Kategori tingkat subordo tergolong Alfisol yang mempunyai rejim kelembaban udik maka tergolong Udalf. Kategori tingkat great group tergolong Alfisol adalah Hapludalf karena semua kriteria yang dimiliki oleh tanah tersebut tidak ada yang sesuai dengan kriteria yang telah pada buku Soil Taxonomy. Kategori tingkat subgrup tidak termasuk Lithic Hapludalf karena tidak mempunyai kontak litik di dalam $50 \mathrm{~cm}$ dari permukaan tanah mineral. Apabila semua kriteria tidak ada yang cocok terhadap sifat-sifat tanah tersebut, maka untuk penamaan kategori subgrup diberikan nama Typic Hapludalf yang memiliki makna Hapludalf yang lain.

Kategori famili yaitu Typic Hapludalf dengan kelas besar butir berlempung. Kelas mineralogi yang terkandung pada tanah tersebut adalah campuran karena setelah dilakukan analisis mengenai mineralogi didapatkan hasil bahwa tidak hanya satu jenis mineral yang terkandung pada tanah tersebut melainkan tiga jenis mineral diantaranya Felspar dengan nilai

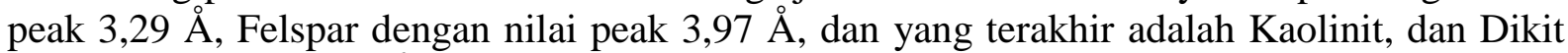
dengan nilai peak 4,38 ̊. Kategori kelas rejim suhu tanah yang terdapat pada lokasi penelitian adalah isohipertermik yang bermakna bahwa suhu tanah tahunan rata-rata adalah $22^{\circ} \mathrm{C}$ atau lebih tinggi, serta perbedaan suhu rata-rata musim kemarau dan musim penghujan $<6^{\circ} \mathrm{C}$. Sehingga kategori tingkat famili tanah untuk profil ini adalah Typic Hapludalf, berlempung, campuran, isohipertermik.

Tanah-tanah yang mempunyai kandungan liat tinggi di horison B (horison argilik) dibedakan menjadi tanah Alfisol. Tanah Alfisol banyak di temukan di daerah beriklim sedang, tetapi dapat pula ditemukan di daerah tropika dan subtropika. Alfisol merupakan tanah yang subur, banyak digunakan untuk pertanian, rumput ternak atau hutan. Tanah ini mempunyai kejenuhan basa yang tinggi. Kapasitas tukar kation tinggi, dan cadangan unsur hara yang banyak. Bahaya erosi yang perlu diperhatikan pada tanah ini ketika horison argilik muncul di permukaan, tanah menjadi kurang baik (liat terlalu tinggi) (Hardjiwigeno, 2003). Salah satu tindakan untuk pengelolaan Alfisol dengan olah tanah konvensional.

Olah tanah konservasi (conservation tillage) menjadi alternatif penyiapan lahan yang dilaporkan dapat mempertahankan produktivitas tanah tetap tinggi Olah tanah konservasi (OTK) adalah cara penyiapan lahan yang menyisakan sisa tanaman di atas permukaan tanah sebagai mulsa dengan tujuan untuk mengurangi erosi dan penguapan air dari permukaan tanah (Rachman et al., 2004). Utomo (1994) mendefinisikan OTK sebagai suatu cara pengelolaan tanah yang bertujuan untuk menyiapkan lahan agar tanaman dapat tumbuh dan berproduksi optimum, namun tetap memperhatikan aspek konservasi tanah dan air.

Peranan OTK dalam mengurangi erosi dan penguapan air dari permukaan tanah karena: (a) keberadaan sisa tanaman dalam jumlah memadai di permukaan tanah; (b) kondisi 
permukaan tanah yang kasar (rough), pori (porous), berbongkah (cloddy), dan bergulud (ridged); atau (c) kombinasi dari keduanya (Mannering and Fenster, 1983). Dengan demikian, nampak jelas bahwa keefektifan OTK ditentukan oleh penggunaan sisa tanaman sebagai mulsa di permukaan tanah.

\section{KESIMPULAN DAN SARAN}

Morfologi dan klasifikasi Alfisol : (a) epipedon molik karena memiliki solum tanah $\geq$ $18 \mathrm{~cm}(23 \mathrm{~cm})$, kandungan C-organik $\geq 0,6 \%(1,29 \%)$, kejenuhan basa $\geq 50 \%(55,72 \%)$ dan value serta chroma $\leq 3$ (value 3 dan chroma 3 ); (b) horison penciri bawah yang dijumpai adalah argilik karena mengandung liat $<15 \%$, maka horison argilik $>3 \%$ (absolut) lebih liat yang terdapat pada horison Bt dibandingkan horison di atasnya; (c) subordo dikategorikan Udalf, great group Hapludalf, subgroup Typic Hapludalf, famili Typic Hapludalf, berlempung, campuran, isohipertermik. Pengelolaan yang sesuai untuk tanah Alfisol yaitu dengan olah tanah konvensional.

Saran dari penulisan ini adalah perlu dilakukan penelitian lanjutan untuk memaksimalkan penggunaan lahan tersebut atau perlu dilakukan tindakan konservasi yang tepat pada lokasi penelitian serta diperlukan upaya yang tepat untuk pengelolaan lahan tersebut.

\section{DAFTAR PUSTAKA}

Arabia, T., Manfarizah, dan A. Karim. 2012. Klasifikasi dan Pengelolaan Tanah. Syiah Kuala University Press, Darussalam - Banda Aceh.

Arifin, S. 1994. Petunjuk Teknis Pengolahan Teh. Pusat Penelitian Teh dan Kina. Gembong, Bandung.

Brown, R. E, J. L. Havlin, D. J. Lyons, C. R. Fenster, and G. A. Peterson. 1991. Longterm tillage and nitrogen effects on wheat production in a wheat fallow rotation. p. 326 In Agronomy Abstracts. Annual Meetings ASA, CSSA, and SSSA (Denver Colorado, Oct 27-Nov 1, 1991).

Dinas Pertambangan dan Energi Provinsi Aceh (Distamben Aceh). 2006. Geo Investigasi Danau Aneuk Laot, Pulau Weh, NAD. Aceh (ID): Dinas Pertambangan dan Energi Provinsi Aceh.

Hakim, N., M. Y. Nyakpa., A. M. Lubis., S. G. Nugroho., M. A. Diha., G. B. Hong., dan H. H. Bailey. 1986. Dasar-dasar Ilmu Tanah. Universitas Lampung, Bandar Lampung.

Hardjowigeno, S. 2003. Ilmu Tanah. Akademika Pressindo, Jakarta.

Mannering, J.V., and C.R. Fenster. 1983. What is conservation tillage. J. Soil and Water Conserv. 38: 151-154.

Nyakpa, M. Y., N. Hakim, A. M. Lubis, M. A. Pulung, G. B. Hong, A. G. Amrah, dan A. Munawar. 1988. Kesuburan Tanah. Universitas Lampung, Bandar Lampung.

Pairunan, A. K. 1985. Dasar-dasar Ilmu Tanah. Badan Kerjasama Perguruan Tinggi Indonesia Timur, Makassar.

Rachman, A., A. Dariah, dan E. Husen, 2004. Olah Tanah Konservasi. Teknologi Konservasi Tanah pada Lahan Kering. Puslitbangtanak. Badan Litbang Pertanian. Departemen Pertanian 2004.

Soil Survey Staff. 2014. Keys to Soil Taxonomy. $11^{\text {th }}$ ed. USDA, NRCS, Washington. Utomo, W. H. 1994. Erosi dan Konservasi Tanah. Malang: Penerbit IKIP, Malang. 